\title{
Prevalence of Ailments in a Youth Camp in Southern Nigeria
}

\author{
Cyprian Chuks Odega ${ }^{1, *}$, Kehinde Charles Mofolorunsho ${ }^{2}$ \\ ${ }^{1}$ South-South Area Office, National Youth Service Corps, Asaba, Nigeria \\ ${ }^{2}$ Department of Microbiology, Faculty of Natural Sciences, Kogi State University, Anyigba, Nigeria
}

\section{Email address:}

triplecode21@yahoo.com (C. C. Odega), ckmofolorunsho@gmail.com (K. C. Mofolorunsho)

${ }^{*}$ Corresponding author

\section{To cite this article:}

Cyprian Chuks Odega, Kehinde Charles Mofolorunsho. Prevalence of Ailments in a Youth Camp in Southern Nigeria. Central African Journal of Public Health. Vol. 6, No. 6, 2020, pp. 346-350. doi: 10.11648/j.cajph.20200606.15

Received: November 4, 2020; Accepted: November 19, 2020; Published: December 16, 2020

\begin{abstract}
Background: The National Youth Service Corps organizes a three-week orientation course for young Nigerian graduates who graduated at less than 30 years of age from polytechnics or Universities either in Nigeria or outside Nigeria. They are sent to an orientation camp in the state of deployment. This camp brings together the graduate youths and many camp officials from several organizations. Objective: This study was carried out to assess the prevalence of diseases in NYSC camp in Delta State, southern Nigeria. Method: Case notes of all who accessed health care from the camp clinic for the 3 weeks of the orientation course were retrieved to get their demographic details, dates of presentation at the clinic and ailments. These were analyzed and frequency counts and percentages obtained for them. Results: Of the 1,249 persons that presented to the clinic, $92.2 \%$ were corps members, $50.2 \%$ were males and $92.2 \%$ were Christians. Some of the patients visited the clinic up to 3 different times. Upper respiratory tract infection was most prevalent with $30.9 \%, 33.3 \%$ and $22.2 \%$ prevalence for $1^{\text {st }}, 2^{\text {nd }}$ and $3^{\text {rd }}$ visits respectively. Uncomplicated malaria was next most prevalent ailment on camp and was also the most common associated ailment with upper respiratory tract infection. Most of the visits to the camp clinic were in the $1^{\text {st }}$ and $2^{\text {nd }}$ week of the orientation course. Conclusion: While URTI and uncomplicated malaria were the most common ailments report, there was no record of outbreak of infectious disease on the camp for the period.
\end{abstract}

Keywords: Youth, Camp, Prevalence, Diseases, Southern Nigeria

\section{Introduction}

The National Youth Service Corps (NYSC) programme is a Scheme set up by the Nigerian Government for one year mandatory service for all Nigerian graduates of universities and polytechnics graduating at less than 30 years of age who studied full time in their various institutions [1]. The NYSC programme has four cardinal programmes. The first of which is the Mobilization and orientation course [2]. The orientation is a three-week exercise where young Nigerian graduates are brought together from different institutions of study within and outside the country, states of origin and residence to the orientation camp in their state of deployment. It is done in such a way that the entire nation is represented by the graduates in each orientation camp [1].

The NYSC camp is not only popular among the youths but also among different strata of the society due to the impact of the Scheme on the different sectors of the society. The camp has been holding since the inception of the Scheme in 1973 and currently holds 3 to 6 times a year in different locations across the Federation. The Scheme which mobilized 2,364 graduates at inception, now mobilizes over 300,000 graduates every service year [3]. These thousands of graduates mobilized annually are deployed to any of the 36 States and the Federal Capital Territory where they are expected to participate in orientation course at the orientation camp located in the state of deployment. During the orientation exercise, corps members are involved in different activities which include sports, drills, physical training, lectures, socials, citizenship and leadership training.

Although camping enables participants make new friends, meet different people, gain self-confidence and participate in a variety of new activities, these opportunities can inadvertently expose campers to a wide spectrum of illnesses and injuries depending on the environment and scope of activities [4, 5]. Concerns have been raised from different quarters at different 
times in camps. One of such concerns is the state of health of the participants which clearly is one of the most important responsibilities during the camp season [6]. Gautret and Steffen stated that mass gatherings are characterized by concentration of people temporally and spatially, and may lead to the emergence of infectious diseases due to enhanced transmission between attendees [7]. NYSC camps are one of such programmes that bring lots of persons together.

As of today, there is a dearth of research that has assessed health related issues including the epidemiology of various communicable diseases in NYSC orientation camps despite the over four decades of the Scheme's existence. This study therefore aims to investigate the prevalence of diseases in one of the camps.

\section{Methodology}

\subsection{Study Population and Setting}

The study was conducted in the NYSC orientation camp in Delta State, South-South Nigeria during the orientation course in August 2014. The population in the camp comprises corps members deployed to the state, camp officials (NYSC staff; personnel of the Nigerian Army, Man O'War, Nigerian Police, Nigerian Security and Civil Defence Corps, Nigerian Red Cross, Department of State Services, National Drug Law Enforcement Agency, Federal Tertiary Health Facility, Fire Service; gardeners, cleaners, cooks and stewards) and camp market operators. The camp can accommodate over 4,000 persons including 3,000 corps members and 500 camp officials for any orientation course. Delta State NYSC Permanent Orientation camp is situated at Issele-uku, Aniocha North Local Government Area of Delta State. The town is the headquarters of the local government area and it is located at $6^{\circ} 19^{\prime} \mathrm{N}$ and $6^{\circ} 28^{\prime} \mathrm{E}$ [8]. It is in the rainforest region of Nigeria with rainy season from March to October and dry season from November to February. So the orientation course for this study held in the middle of the rainy season with its attendant cold weather and lots of mosquitoes. The camp has a central kitchen from where officials and corps members are fed and functional borehole that provides potable water for the entire camp community. There is also a camp clinic which has a staff coordinating its activities and is manned by the corps medical personnel (doctors, nurses, laboratory scientists, physiotherapists, pharmacists, dentists, optometrists etc.) that are a part of the graduates posted to that camp. These corps medical personnel are supervised by Consultants and senior nursing officers from Federal Medical Centre, Asaba. This camp clinic serves the health needs of the entire camp. All the course participants (corps members and officials) constitute the study population while the study subjects are those who assessed care at the camp clinic during the orientation exercise.

\subsection{Data Collection and Analysis}

The medical team takes note of every case that presents to the clinic by noting the date of visit, person's name, age, sex, registration number, clinic number, religion, school attended, state of origin, course studied, case or complaint, revisits. This is done on plain papers which are arranged into 10 different folders, one for each of the platoons (which are always 10 in number for ease of corps members' administration) and a separate folder for the camp officials.

These case notes for all that sought health care from the clinic were reviewed by a medical doctor to ascertain the ailments as documented. These were entered into the statistical software, Statistical Package for Social Sciences (SPSS) (version 20). Data was cleaned and organized before analysis. Frequency counts and percentages were obtained for all the variables of interest.

\section{Results}

Records of 1,249 persons seen by the camp clinic were obtained for the study. The patients were at the clinic between $5^{\text {th }}$ (day camp opened) and $25^{\text {th }}$ August, 2014 (eve of closure of camp). Of the patients with record of camp status, $92.2 \%(1,061)$ were corps members while $7.8 \%$ (90) were camp officials. Males made up 50.2\% (597) of the patients and $49.8 \%$ (593) were females. The age of the clinic patients ranged from 3 months to 58 years, with a mean, mode and median age of $26.099( \pm 4.2763), 26.00$ and 25.0 years respectively. Most of the patients $(82.7 \%)$ were single and also, majority (87.2\%) were Christians. Most of them (62.9\%) were from the South East geo-political zone of the country, followed by the South West $(17.1 \%)$. The North East geo-political zone had the least $(0.2 \%)$ of the patients. In terms of location of school where they graduated from, South East geopolitical zone also had the highest with $47.1 \%$ (511) of the patients seen, while North East zone had the least with $1.3 \%$ (14). For course of study, those from Social Sciences/Administration background had the largest number of patients to the clinic $(36.7 \%=396)$ followed by Biological/Agricultural/Environmental Sciences graduates $(13.8 \%=149)$. The law graduates were the least $(0.4 \%=4)$ of those who visited the clinic. Of those who visited the clinic for the first time, $13.0 \%$ were diagnosed of 2 different ailments. The most prevalent in first diagnosis was upper respiratory tract infection (URTI) - 30.9\% and uncomplicated malaria $-28.5 \%$. Trauma was next $-8.6 \%$. For the $2^{\text {nd }}$ diagnosis (during $1^{\text {st }}$ visit), uncomplicated malaria was most $(31.5 \%)$ followed by trauma $(9.3 \%)$. Two hundred and three $(17.1 \%)$ were either admitted or came back for revisit at the clinic. While $13.1 \%$ of them were treated for same ailment as before, $8.3 \%$ had complications from the earlier treatment while $78.6 \%$ came on account of new ailment. For the new ailment during the revisit to the clinic, 33.3\% had URTI, $25.9 \%$ had uncomplicated malaria, and other $8.0 \%$ had trauma. Among them, 27 (2.2\%) were diagnosed of a second ailment and the diagnosis included uncomplicated malaria - 22.2\% (6), and PUD - 11.1\% (3). The revisit or admission was between $6^{\text {th }}$ August and $25^{\text {th }}$ August, 2014 with the most revisits/admission being on $18^{\text {th }}$ August with $11.1 \%$ followed by $14^{\text {th }}$ August with $10.1 \%$. 
Thirty-two $(16.6 \%)$ of those who presented a $2^{\text {nd }}$ time to the clinic also presented a $3^{\text {rd }}$ time of which $31.3 \%$ (10) was a follow-up to the previous visit while $62.5 \%$ (20) was as a result of new complaints. For the new complaints at the $3^{\text {rd }}$ visit, URTI was majority with $31.8 \%$, followed by uncomplicated malaria (18.2\%), followed by trauma (13.6\%). The second revisit was from $10^{\text {th }}$ August to $25^{\text {th }}$ August, 2014 with the most being on $18^{\text {th }}$ August, 2014, (15.2\%) and followed by $15^{\text {th }}$ and $21^{\text {st }}$ August that had $12.1 \%$ each of the revisits.

Table 1. Demographics.

\begin{tabular}{|c|c|}
\hline Corps members & $1,061(92.2 \%)$ \\
\hline \multirow[t]{2}{*}{ Camp officials } & $90(7.8 \%)$ \\
\hline & Range: 3 months -58 years \\
\hline \multirow{3}{*}{ Age } & Mean: $26.099 \pm 4.2763$ \\
\hline & Median: 26.00 years \\
\hline & Mode: 25.00 years \\
\hline \multirow{3}{*}{ Sex } & Male $-597(50.2 \%)$ \\
\hline & Female - $593(49.8 \%)$ \\
\hline & Single $-1,033(88.0 \%)$ \\
\hline \multirow[t]{3}{*}{ Marital Status } & Married - $140(11.9 \%)$ \\
\hline & Others $-1(0.1 \%)$ \\
\hline & Christianity - 1,089 (92.8\%) \\
\hline \multirow[t]{4}{*}{ Religion } & Muslim - $84(6.7 \%)$ \\
\hline & Others $-1(0.1 \%)$ \\
\hline & South East - $681(62.9 \%)$ \\
\hline & South West - 214 (19.8\%) \\
\hline \multirow{6}{*}{ Origin } & South South - $140(12.9 \%)$ \\
\hline & North East $-2(0.2 \%)$ \\
\hline & North West - $10(0.9 \%)$ \\
\hline & North Central - 35 (3.2\%) \\
\hline & South East - $511(47.1 \%)$ \\
\hline & South West - 284 (26.2\%) \\
\hline \multirow{7}{*}{$\begin{array}{l}\text { Location of } \\
\text { school attended }\end{array}$} & South South - $148(13.7 \%)$ \\
\hline & North East - 14 (1.3\%) \\
\hline & North West - $27(2.5 \%)$ \\
\hline & North Central - $64(5.9 \%)$ \\
\hline & Other countries $-36(3.3 \%)$ \\
\hline & Medicine/Medical Sciences - 41 (3.8\%) \\
\hline & $\begin{array}{l}\text { Biological/Agricultural/Environmental Sciences - } 149 \\
(13.8 \%)\end{array}$ \\
\hline \multirow{5}{*}{ Course of study } & Physical Sciences - $133(12.3 \%)$ \\
\hline & Engineering - $140(13.0 \%)$ \\
\hline & Arts/Humanities - 122 (11.3\%) \\
\hline & Social Sciences/Administration - 396 (36.9\%) \\
\hline & $\mathrm{Law}-4(0.4 \%)$ \\
\hline
\end{tabular}

Table 2. Clinic attendance.

\begin{tabular}{ll}
\hline Date of attending clinic: & \\
$5^{\text {th }}-11^{\text {th }}$ August, 2014 & $482(40.4 \%)$ \\
$12^{\text {th }}-18^{\text {th }}$ August, 2014 & $504(42.3 \%)$ \\
$19^{\text {th }}-25^{\text {th }}$ August, 2014 & $206(17.3 \%)$ \\
Diagnosis $1 \mathrm{a}\left(1^{\text {st }}\right.$ diagnosed aliment at $1^{\text {st }}$ visit): & \\
Upper Respiratory Tract Infection & $367(30.9 \%)$ \\
Uncomplicated malaria & $338(28.5 \%)$ \\
Trauma & $102(8.6 \%)$ \\
Myalgia & $55(4.6 \%)$ \\
Peptic ulcer disease & $43(3.6 \%)$ \\
Enteritis & $30(2.5 \%)$ \\
Others & $253(21.3 \%)$ \\
Diagnosis $1 b\left(2^{\text {nd }}\right.$ diagnosed ailment at $1^{\text {st }}$ visit): & \\
Uncomplicated malaria & $51(31.5 \%)$ \\
Trauma & $15(9.3 \%)$ \\
Myalgia & $13(8.0 \%)$ \\
\hline
\end{tabular}

\begin{tabular}{ll}
\hline Peptic ulcer disease & $10(6.2 \%)$ \\
Others & $14(8.6 \%)$ \\
Follow-up/Admission: & \\
Yes & $203(17.1 \%)$ \\
No & $985(82.8)$ \\
Date of follow-up/Admission: & \\
$6^{\text {th }}-11^{\text {th }}$ August, 2014 & $29(14.0 \%)$ \\
$12^{\text {th }}-18^{\text {th }}$ August, 2014 & $106(51.2 \%)$ \\
$19^{\text {th }}-25^{\text {th }}$ August, 2014 & $72(34.8 \%)$ \\
Issue for revisit: & \\
Follow-up on last diagnosis & $27(13.1 \%)$ \\
Complications from last diagnosis & $17(8.3 \%)$ \\
New ailment & $162(78.6 \%)$ \\
Diagnosis 2a (1 $1^{\text {st }}$ diagnosed ailment during $1^{\text {st }}$ revisit): & \\
Upper Respiratory Tract Infection & $54(33.3 \%)$ \\
Uncomplicated malaria & $42(25.9 \%)$ \\
Trauma & $13(8.0 \%)$ \\
Others & $53(32.7 \%)$ \\
Diagnosis $2 \mathrm{~b}\left(2^{\text {nd }}\right.$ diagnosed ailment during $1^{\text {st }}$ revisit): & \\
Uncomplicated malaria & $6(22.2 \%)$ \\
Peptic ulcer disease & $3(11.1 \%)$ \\
Others & $18(66.7 \%)$ \\
$2^{\text {nd }}$ revisit: & \\
Yes & $32(16.6 \%)$ \\
No & $161(83.4 \%)$ \\
Date of $2^{\text {nd }}$ revisit: & \\
$10^{\text {th }}-11^{\text {th }}$ August, 2014 & $1(3.0 \%)$ \\
$12^{\text {th }}-18^{\text {th }}$ August, 2014 & $18(54.6 \%)$ \\
$19^{\text {th }}-25^{\text {th }}$ August, 2014 & $14(42.4 \%)$ \\
Issue of revisit: & \\
Follow-up on last visit & $10(31.3 \%)$ \\
Complication of previous ailment & $2(6.3 \%)$ \\
New ailment & $20(62.5 \%)$ \\
Diagnosis 3a: & \\
Upper Respiratory Tract Infection & $7(31.8 \%)$ \\
Uncomplicated malaria & $4(18.2 \%)$ \\
Trauma & $3(13.6 \%)$ \\
Others & $8(36.4 \%)$ \\
\hline & \\
\hline
\end{tabular}

\section{Discussion}

Majority of the patients that presented at the clinic were corps members $(92.2 \%)$. This can be attributed to the fact that more corps members than officials are always present in any orientation camp during orientation exercises. It is also in consonance with the study of Maori et al where more corps members presented to the camp clinic than other categories of persons in the camp [9]. Slightly more males (50.2\%) accessed health care at the camp clinic more than females. While this phenomenon cannot be readily explained, it is different from the result of the study of Maori et al which reported that more females reported to the camp clinic [9]. Majority $(88.0 \%)$ of those who came to the clinic were single, which can be explained that it is a youth camp and that most of the corps members, who form majority of the camp population were single at the time of going to the camp. It was also noted that most $(92.8 \%)$ of those who came to the clinic were Christians. This can be as result of majority of the clinic attendees being from the southern part of the country which is predominantly Christians. Those who originated from the South East geo-political region of the country as well as those who schooled there (South-East geo-political zone) were the highest among the clinic attendees. This may be due to the fact 
that most of the corps members in camp either originated there or schooled there.

Considering course of study, those from Social Sciences/Administration disciplines had the highest (36.9\%), followed by those from Biological/Agricultural/Environmental Sciences background $(13.8 \%)$. The law graduates were the least with $0.4 \%$ of those that attended the clinic. This could also be explained on the basis of the number of persons from the respective disciplines that were deployed to the camp for that particular orientation. For clinic attendance, $42.3 \%$ of the attendance was in the $2^{\text {nd }}$ week of the 3-week orientation course, and is slightly higher than that of the $1^{\text {st }}$ week $(40.4 \%)$, while the $3^{\text {rd }}$ week was low $(17.3 \%)$. This may be due to the fact that all the physical activities and training had all started by the end of the $1^{\text {st }}$ week and intensified in the $2^{\text {nd }}$ week there by making more people have need to access health care at the clinic. Whereas for the $3^{\text {rd }}$ week, many of the persons in the camp had become accustomed to the routine and rigors of the camp and so fewer persons had to make use of the clinic. It could also be as a result of the infections having passed the incubation period and so manifested in the patients as majority of the ailments were URTI and malaria. URTI has an incubation period of 1-5 days for URTI caused by Rhinoviruses and group A streptococci [10] and 9-14 days for Plasmodium falciparum which causes malaria [11].

The results also show that upper respiratory tract infection (URTI) with $30.9 \%$ was the most common ailment diagnosed in the clinic. This was followed closely by uncomplicated malaria with $28.5 \%$. It is worthy to note that uncomplicated malaria also topped the list of secondary diagnosis at $1^{\text {st }}$ visit with $31.5 \%$ for those patients diagnosed with 2 different ailments at their $1^{\text {st }}$ visit to the clinic. This uncomplicated malaria was mostly associated with URTIs. This study is consistent with that of Ide and Uchenwa-Onyenegecha who stated that acute respiratory infections (ARI) are the most common reason most person access health services around the world and that most cases of ARI seen were URTIs [12]. Akanbi et al also stated that ARIs are the major cause of hospital admission and death in Nigerian children [13]. It is also consistent with the study of Ujunwa and Ezeonu that reported the most frequent associated diagnosis with URTI to be malaria [14]. The large number of URTI can also be linked to the season (rainy season) that this particular camp held as the finding of Ide and Uchenwa-Onyenegecha reported more cases of ARI during the peak of the rainy season [12]. They also opined that the higher number of cases seen during the rainy season may be due to the reduction in atmospheric temperature during the season. Large number of URTIs reported could also be linked to intense activities going on in the camp as the study of Galazka-Franta et al stated that intense exercise causes a temporary decrease in the immune system function and that intense exercise necessary in competitive sports is related to a three times higher incidence of URTIs [15]. This finding supports the result above where most of the cases were seen in the $1^{\text {st }} 2$ weeks of the camp when activities started and became more intensified. Of all the patients that visited the clinic, $17.1 \%$ came back for a revisit. Out of these, $78.6 \%$ of them came to the clinic on account of a new ailment. During this $1^{\text {st }}$ revisit, URTI topped the list of ailments diagnosed with $33.3 \%$, followed by uncomplicated malaria $(25.9 \%)$. Just like it was in the $1^{\text {st }}$ visit, uncomplicated malaria topped the list of secondary diagnosed ailments with $22.2 \%$. This is in line with the earlier stated findings that ARI was the most common reason that people access health care and that malaria was the most common ailment associated with URTI [12-14]. Few persons $(32=16.6 \%)$ of those who visited the clinic a $2^{\text {nd }}$ time came back a $3^{\text {rd }}$ time ( $2^{\text {nd }}$ revisit). Of these, $62.5 \%$ reported back to the clinic on account of a new ailment and URTI was the most common ailment among them with $31.8 \%$ prevalence followed by uncomplicated malaria with $18.2 \%$. Generally, it can be concluded that URTI was the most common infection treated at all times in the clinic and during the different visits followed by uncomplicated malaria. This may be as a result of the weather condition at the time of the orientation exercise and also that intense activities may have temporarily decreased the immune system function of the orientation camp participants as was in line with the findings by GalazkaFranta et al [15]. There is also the possibility of a change of environment and the issue of adjusting to the camp environment. The diseases recorded did not show any infectious disease outbreak for the 3 weeks orientation exercise.

\section{Conclusion}

The orientation camps have been in existence since the inception of the NYSC Scheme in 1973 but there is no known study of the diseases prevalence in the respective camps. While it is worth mentioning that there has not been any known issue of outbreak in camps, there is the need for a conscious study of diseases prevalent in the various camps and at different seasons and possibly patterns of occurrence. Knowledge of the prevalence of disease and patterns of occurrence on camps will be very useful in resource allocation, and long-term planning of orientation exercises. The study has several limitations: The diagnoses recorded were based on doctor's clinical observation and there was no test for confirmation of the ailments. Also being the first known study of its kind to study disease prevalence in an NYSC camp in Nigeria, there is no documentary or published work for comparison.

\section{References}

[1] National Youth Service Corps Act. Cap N84 Laws of the Federation of Nigeria, 2004.

[2] National Youth Service Corps. (2012). Inspectors' Manual.

[3] NYSC News. (2017). 44 ${ }^{\text {th }}$ Anniversary Commemorative Edition. 
[4] Yard, E. E., Scanlin, M. M., Erceg, L. E., Powell, G. M., Wilkin, J. R. $3^{\text {rd }}$, Knox, C. L. \& Comstock, R. D. (2006). Illness and injury among children attending summer camp in the United States, 2005. Pediatrics 118 (5): 1342-9.

[5] Miller, R. T. \& Barth, E. B. (2016). Health Supply Utilization at a Boy Scout Summer Camp: An Evaluation for Improvement and Preparedness. Wilderness and Environment Medicine 27 (4): 482-491.

[6] Papageorgiou, P., Mavrommatis, G. \& Costa, G. (2008). Camp Sports Injuries: Analysis of Causes, Modes and Frequencies. International Journal of Sport Management Recreation \& Tourism 2: 14-25.

[7] Gautret, P. \& Steffen, R. (2006). Communicable diseases as health risks at mass gatherings other than Hajj: what is the evidence? International Journal of Infectious Diseases Vol. 47. Pp 46-52.

[8] Issele Uku Map - Satellite images of Issele Uku. maplandia.com/Nigeria/delta/aniochan/issele-uku/. Assessed on $06 / 07 / 2020$.

[9] Maori L., Jimoh, A., Shittu, A. N., Raji, A. A., Eigege, E., Anaryu, J. J., Musa, A., Ishaya, V., Gyang, P. C., Afolabi, A. A., Agbor, V. O. \& Onyilo M. (2017). Prevalence of Malaria Parasite among NYSC Corps members, Staff, Military and Paramilitary who reported at NYSC Orientation Camp Amada in Gombe State. Greener Journal of Epidemiology and Public Health 5 (2): 006-010. Downloaded online on 09/07/2020.
[10] Meneghetti, A. (2018). What are the incubation periods for upper respiratory tract infections (URIs)? www.medscape.com Downloaded on 04/04/2020.

[11] Gompf, S. G. (2019). What facts should you know about malaria? www.emdicinehealth.com Downloaded on $04 / 04 / 2020$

[12] Ide, L. E. Y. \& Uchenwa-Onyenegecha, T. A. (2015). Burden of Acute Respiratory Tract Infections as Seen in University of Port Harcourt Teaching Hospital Nigeria. Journal of US-China Medical Science 12: 158-162. Donwloaded online from http://www.davidpublisher.org/Public/uploads/Contribute/568 4e14c7c096.pdf on 09/07/2020.

[13] Akanbi, M. O., Ukoli, C. O., Erhabor, G. E., Akanbi, F. O. \& Gordon, S. B. (2009). The burden of respiratory disease in Nigeria. African Journal of Respiratory Medicine Downloaded from https://pdfs.semanticscholar.org/bae8/1a509edb2e6fldbc5dd31f3 ecc656d963921.pdf on 09/07/2020 on 09/07/2020.

[14] Ujunwa, F. A. \& Ezeonu, C. T. (2014). Risk Factors for Acute Respiratory Tract Infections in Under-five Children in Enugu Southeast Nigeria. Ann Med Health Sci Res. 4 (1): 95-99. Downloaded from https://www.ncbi.nlm.nih.gov/pmc/articles/PMC3952306/?rep ort=printable on $09 / 07 / 2020$.

[15] Galazka-Franta, A., Jura-Szoltys, E., Smolka, W. \& Gawlik R. (2016). Upper Respiratory Tract Diseases in Athletes in Different Sports Disciplines. J Hum Kinet 53 (1): 99-106. Downloaded online on 09/07/2020. 